\section{Estimation of Toothpaste Fluoride Intake in Preschool Children}

Helena Aguiar Ribeiro do Nascimento ${ }^{1}$, Jainara Maria Soares Ferreira ${ }^{2}$, Ana Flávia Granville-Garcia' ${ }^{1}$, Edja Maria Melo de Brito Costa ${ }^{1}$, Ana Lúcia Almeida Cavalcante $^{3}$, Fábio Correia Sampaio ${ }^{3}$

\author{
'Department of Dentistry, UFPB \\ - State University of Paraíba, \\ Campina Grande, PB, Brazil \\ ${ }^{2}$ Department of Dentistry, UNIPE \\ - University Center of João \\ Pessoa, João Pessoa, PB, Brazil \\ ${ }^{3}$ Department of Clinic and Community \\ Dentistry, UFPB - Federal University \\ of Paraíba, João Pessoa, PB, Brazil
}

Correspondence: Profa. Dra. Jainara Maria Soares Ferreira, Avenida Mar da Noruega, 66/303, Intermares, 58310-000 Cabedelo, PB, Brasil. Tel: +55-83-8833-0315. e-mail: jainara.s@ig.com.br

\begin{abstract}
The objective of this study was to estimate the intake of toothpaste fluoride used by children aged 2 to 6 years $(n=87)$ treated at a hospital of a medium-sized city (Campina Grande, PB) in the Northeastern region of Brazil. Data regarding sociodemographic characteristics of families and children's toothbrushing were collected from questionnairebased interviews with parents/guardians, and the amount of fluoride used during toothbrushing was estimated using a precision scale for assessment of the risk of dental fluorosis, considering a cutoff value of $0.07 \mathrm{mgF} / \mathrm{kg}$ body weight/day. Fluoride content in the toothpastes was analyzed using a specific fluoride electrode. Data were analyzed using descriptive and inferential statistics using the chi-square and Fisher's exact tests $(\alpha=0.05)$. Considering the use of the dentifrice, the risk of fluorosis in the children was $19.5 \%$. There was significant association $(p<0.05)$ between the risk of fluorosis, brushing frequency, type of dentifrice and who performed the child's oral hygiene. It was concluded that a high percentage of children in the studied sample used toothpaste inappropriately and were at risk of developing dental fluorosis.
\end{abstract}

\section{Introduction}

In recent decades, there has been a worldwide decline in the prevalence and severity of dental caries, even in countries with unstable market economy (1). However, simultaneous to such reduction, there has been increase in dental fluorosis in locations where the public water supply is not fluoridated $(2,3)$.

One of the most widely accepted measures for control of dental caries is brushing with fluoridated toothpaste, as it combines the mechanical biofilm removal to the therapeutic properties of fluoride (4). In order to a dentifrice have anticaries potential, it must have fluoride (F) at the minimum concentration of $1000 \mathrm{ppm}$, which must be soluble in the formulation (5). Therefore, if used at optimal levels, fluoride has highly beneficial effects in preventing and controlling dental caries (6). However, if fluoride is ingested in excessive doses and high frequency at the time of tooth formation, this halogen may lead to the emergence of developmental structural changes known as dental fluorosis, characterized by patches of enamel (7).

The association between early use of fluoride dentifrice and the prevalence of dental fluorosis is widely reported in the literature in fluoridated and non-fluoridated regions (8-11). The ingestion of fluoride toothpaste before the age of 6 is identified as one of the main risk factors for dental fluorosis $(8,12)$.

The aim of this study was to estimate the fluoride intake from toothpaste in preschoolers, considering the risk of dental fluorosis in face of an inadequate chronic ingestion of this product during toothbrushing.

\section{Material and Methods}

A cross-sectional study was conducted including children aged 2 to 6 years who were waiting for medical consultation at a hospital in the city of Campina Grande, $\mathrm{PB}$, a medium-sized city in the northeastern region of Brazil. The sample was calculated by the statistical program Epi Info 6.04 from a population of 825 children, summing up 87 children with 95\% confidence level, 10\% error and $50 \%$ power.

Interviews based on a questionnaire containing questions about sociodemographic characteristics and the use of children's fluoride toothpaste were conducted with parents/guardians by a previously trained researcher in a pilot study with $10 \%$ of the sample not included. After this stage, children's toothbrushes (Tek Jr.; Johnson \& Johnson, São Paulo, SP, Brazil) were distributed to the children and the parents/guardians reported to use one of the following fluoride toothpastes: Tandy ${ }^{\oplus}$, Smile ${ }^{\circledast}$, Colgate ${ }^{\oplus}$ and Colgate ${ }^{\oplus}$ kids (Colgate, São Paulo, SP, Brazil), and Even ${ }^{\oplus}$ and Even kids $^{\circledast}$ (Grupo Raymundo da Fonte, Paulista, PE, Brazil). Then, the parents/guardians were asked to simulate the amount of toothpaste placed on the child's brush at home to perform the oral hygiene. The amount of dentifrice on the brush used by each child was measured by the brush weight difference before and after dentifrice insertion, both measured on a precision scale 500G JL-6 (Western, China). The child's weight was obtained by scale (Welmy, Santa Barbara d'Oeste, SP, Brazil).

The concentrations of fluoride in the different brands of toothpastes were measured after acidic digestion in $2 \mathrm{M}$ 
$\mathrm{HCl}$ at $45^{\circ} \mathrm{C}$ under constant agitation for $2 \mathrm{~h}$ as described elsewhere (19). Fluoride concentration in the toothpaste samples were assessed in triplicate using a specific ion electrode (combined F- electrode 96-09; Orion Res. Inc., Jacksonville, $\mathrm{FL}, \mathrm{USA}$ ) coupled to a $\mathrm{pH} / \mathrm{mV}$ meter (Orion 720A; Orion Res. Inc.). Calibration curves were drawn using standards that ranged from 4 to $64 \mathrm{ppm} \mathrm{F}$.

The values of dentifrice fluoride intake during toothbrushing (VDFI, in $\mathrm{mgF} / \mathrm{kg}$ bodyweight/day) were calculated considering the toothpaste weight on the brush (TW, in g), daily brushing frequency (BF), toothpaste's fluoride concentration in ppm (TFC), dentifrice weight informed on the tube (DW, in g), the child's weight (CW, in $\mathrm{kg}$ ) and the estimated percentage of toothpaste intake (PTI) according to the child's age, using the following equation: $\mathrm{VDFI}=\{[(\mathrm{TW} \times \mathrm{BF}) \times \mathrm{TFC} / \mathrm{DW}] / \mathrm{PC}\} \times \mathrm{PTI}$. The percentage of dentifrice ingestion used during toothbrushing, was $64 \%$, $49 \%, 49 \%, 42 \%$ and $34 \%$ for children aged $2,3,4,5$ and 6 years, respectively (13). The cutoff point for fluorosis risk was $0.07 \mathrm{mgF} / \mathrm{kg}$ body weight/day (2).

Data were analyzed using the SPSS v.13 statistical software (SPSS Inc., Chicado, IL, USA) and presented in form of descriptive statistics, by absolute and percent numbers, and inferential statistics, using the nonparametric chi-square and Fisher's exact tests. The significance level was set at 5\%. This study was approved by the institutional Ethics Committee (CAAE 0346.0.133.000-11).

\section{Results}

Most children were aged 2 years (Fig. 1) and males (51.7\%) predominated over females (48.3\%).

With respect to sociodemographic characteristics, most children's parents/guardians were aged between 18 and 30 years, female, married, with high-school education level and family income of 1 minimum wage or less.

A significant association was found between children's age and who performed toothbrushing. It was also found that parents/guardians performed 95.5\% $(n=42)$ of brushing on younger children ( 2 and 3 years) and 58.1\% $(n=25)$ of older children (4 to 6 years) brushed their own

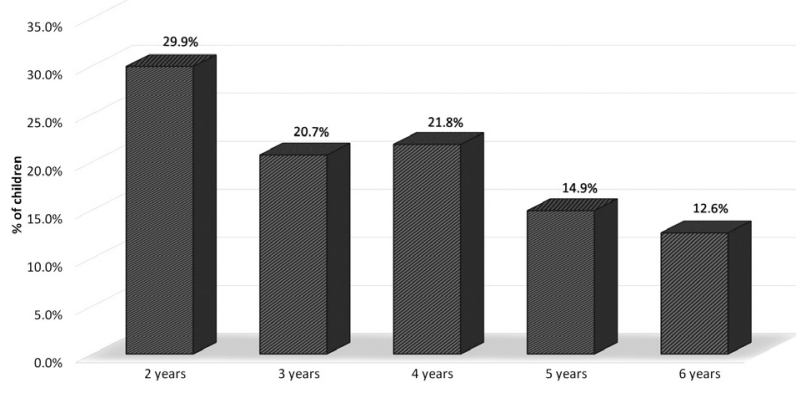

Figure 1. Age distribution of children, Campina Grande, PB, Brazil, 2011 teeth unsupervised $(p<0.05)$.

The amount of fluoride in the toothpastes was usually $30 \%$ lower than stated in the labels, indicating that no toothpaste brand presented values above 1,450 ppm F. Taking into account these values the percentage of children at risk for dental fluorosis can drop from $37.9 \%$ to $19.5 \%$. The risk of dental fluorosis risk according to the dentifrice is presented in Tables 1 and 2.

No relationship was found between the risk of fluorosis and the sociodemographic variables of parents/guardians (family income, schooling and marital status of guardians, age and gender of child) (Table 1).

Regarding the variables related to oral hygiene of children, significant association $(\mathrm{p}<0.05)$ was found among risk of fluorosis, brushing frequency and type of toothpaste (Table 2).

\section{Discussion}

Results of this study indicated inappropriate use of fluoridated toothpaste, since this product alone could contribute to determine the risk of fluorosis in children below 6 years of age. These results are confirmed by the literature (8-11). In contrast, this study reported that the high risk for developing fluorosis might be related to other risk factors in addition to the inappropriate use of fluoridated toothpaste (14).

There was no statistically significant association between the risk of fluorosis and family income, schooling or marital status of guardians. Agreeing with this result, another study found no association between low socioeconomic status and risk of dental fluorosis (15).

Although the literature reports a relationship between the child's age and the risk of fluorosis (16-19), in the present study no association was observed of these variables.

There was no significant association between gender and risk of fluorosis in this study. Studies on gender and prevalence of fluorosis showed similar results $(20,21)$.

Although the amount of fluoride ingested from toothpaste is associated with the habits of spitting and rinsing the mouth during and/or after brushing (22), no statistically significant association was found between these habits and the risk of dental fluorosis in this study.

There was no significant difference between the risk of fluorosis and source of drinking water. Since Campina Grande, located in northeastern Brazil, does not have fluoridated water and does not have wells with high concentration of fluoride, these sources of fluoride seem unlikely (23). Similarly, there was no statistically significant difference between the risk of fluorosis and intake of processed (bottled or canned) juice or mineral water, although presence of fluoride is evident in these products. 
However, further studies should be conducted to assess the total fluoride intake as an estimate for the risk for fluorosis.

It is recommended use of fluoridated toothpaste with approximately 1000 ppm $F(24)$ for children less than 6 years, with daily brushing twice a day and an amount similar to a pea grain $(24,25)$. In addition, it is essential to assess the risk/benefit, including the risk or the patient's caries activity, frequency and exposure to fluoride, due to the risks of chronic toxicity and emergence of dental fluorosis.

It was found that when parents performed children's toothbrushing the risk of fluorosis was significantly higher. This result may be due to the fact that younger children's brushing was performed by their parents/guardians in most cases.

There was a statistically significant association between the risk of fluorosis and the type of toothpaste. This result can be explained by the fact that children's toothpaste are more attractive to children (flavors and colors) when compared to adults, leading to a more frequent use by children. Reinforcing this hypothesis, the frequency of toothbrushing was associated with the risk of fluorosis, where the children that brushed their teeth three times or more a day had higher risk of developing fluorosis than those who brushed twice or less. A study from the literature showed that higher frequency in use of fluoridated toothpaste did not imply a statistically significant risk of fluorosis, disagreeing with the present results (8).

From the obtained results, it was found that the most effective measure to minimize the risk of fluorosis might be reducing the amount of dentifrice placed on the toothbrush. Parents must supervise closely toothbrushing of children under the age of 6 , helping them and instructing them on the use of a small amount of toothpaste on the brush, spitting during brushing and rinsing the mouth after brushing in order to avoid ingestion of large amounts of toothpaste.

An important point to be discussed is that in the analyzed toothpastes there was about 30\% less fluoride content as stated on the product package. This drew attention to the possibility of a lower anticaries efficacy

Table 1. Relationship between the risk of dental fluorosis and the sociodemographic variables of respondents. Campina Grande, PB, Brazil, 2011.

\begin{tabular}{|c|c|c|c|c|c|c|}
\hline \multirow{3}{*}{ Variable } & \multicolumn{4}{|c|}{ Risk of dental fluorosis } & \multirow{3}{*}{$\begin{array}{l}\text { Total group } \\
\text { n (\%) }\end{array}$} & \multirow{3}{*}{$\mathrm{p}$ value } \\
\hline & \multicolumn{2}{|c|}{ Yes } & \multicolumn{2}{|c|}{ No } & & \\
\hline & $\mathrm{n}$ & $\%$ & $\mathrm{n}$ & $\%$ & & \\
\hline \multicolumn{7}{|l|}{ 1. Family income } \\
\hline Up to 1 minimum wage & 15 & 88.2 & 50 & 71.4 & $65(74.7)$ & $\mathrm{p}^{(2)}=0.218$ \\
\hline More than 1 minimum wage & 2 & 11.8 & 20 & 28.6 & $22(25.3)$ & \\
\hline \multicolumn{7}{|l|}{ 2. Schooling of guardians } \\
\hline Less than 8 years & 10 & 58.8 & 21 & 30.0 & $31(35.6)$ & $\mathrm{p}^{(1)}=0.026$ \\
\hline 8 years or more & 7 & 41.2 & 49 & 70.0 & $56(64.4)$ & \\
\hline \multicolumn{7}{|c|}{ 3. Marital status of parents/guardians } \\
\hline Single & 6 & 35.3 & 23 & 32.9 & $29(33.3)$ & $\mathrm{p}^{(1)}=0.514$ \\
\hline Married & 11 & 64.7 & 47 & 67.1 & $58(66.7)$ & \\
\hline \multicolumn{7}{|l|}{ 4. Age group of child } \\
\hline 2 to 3 years & 11 & 64.7 & 33 & 47.1 & $44(50.6)$ & $\mathrm{p}^{(1)}=0.194$ \\
\hline 4 to 6 years & 6 & 35.3 & 37 & 52.9 & 43 (49.4) & \\
\hline \multicolumn{7}{|l|}{ 5. Gender of child } \\
\hline Male & 10 & 58.8 & 35 & 50.0 & 45 (51.7) & $\mathrm{p}^{(1)}=0.514$ \\
\hline Female & 7 & 41.2 & 35 & 50.0 & $42(48.3)$ & \\
\hline Total Group & 17 & 19.5 & 70 & 80.5 & 87 (100.0) & \\
\hline
\end{tabular}

(*): Significant difference at 5.0\%. (1): Using the chi-square test. (2): Using Fisher's exact test. 
due to the reduction of these values. This fact should be investigated in future studies.

Within its limitations, it may be concluded that a significant percentage of the surveyed children were at risk of developing dental fluorosis, taking into account the estimated intake of toothpaste fluoride, requiring programs of continuous education to parents/guardians about the risk of dental fluorosis.

Table 2. Relationship between dental fluorosis risk and oral hygiene habits of children. Campina Grande, PB, Brazil, 2011

\begin{tabular}{|c|c|c|c|c|c|c|}
\hline \multirow{3}{*}{ Variable } & \multicolumn{4}{|c|}{ Risk of dental fluorosis } & \multirow{3}{*}{$\begin{array}{c}\text { Total group } \\
\text { n (\%) }\end{array}$} & \multirow{3}{*}{$p$ value } \\
\hline & \multicolumn{2}{|c|}{ Yes } & \multicolumn{2}{|c|}{ No } & & \\
\hline & $\mathrm{n}$ & $\%$ & $\mathrm{n}$ & $\%$ & & \\
\hline \multicolumn{7}{|l|}{ 1. Child drinks } \\
\hline Well or tap water & 9 & 52.9 & 33 & 47.1 & $42(48.2)$ & $p(1)=0.668$ \\
\hline Mineral water or processed juices & 8 & 47.1 & 37 & 52.9 & $45(51.8)$ & \\
\hline \multicolumn{7}{|l|}{ 2. Has the child a toothbrush? } \\
\hline Yes & 17 & 100.0 & 70 & 100.0 & $87(100.0)$ & - \\
\hline No & - & - & - & - & - & \\
\hline \multicolumn{7}{|l|}{2.1 If positive, for adults or children? } \\
\hline Adults & - & - & - & - & - & - \\
\hline Children & 17 & 100.0 & 70 & 100.0 & $87(100.0)$ & \\
\hline \multicolumn{7}{|l|}{ 3. Has the child has a toothpaste? } \\
\hline Yes & 17 & 100.0 & 70 & 100.0 & $87(100.0)$ & - \\
\hline No & - & - & - & - & - & \\
\hline \multicolumn{7}{|l|}{3.1 If positive, for adults or children? } \\
\hline Adults & 1 & 5.9 & 25 & 35.0 & $26(29.9)$ & $\left.\mathrm{p}^{*}\right)=0.016$ \\
\hline Children & 16 & 94.1 & 45 & 64.3 & $61(70.1)$ & \\
\hline \multicolumn{7}{|l|}{ 4. How much of fluoride ppm (brand)? } \\
\hline $1000 \mathrm{ppm}$ or less & 5 & 29.4 & 8 & 11.4 & $13(14.9)$ & $p(2)=0.121$ \\
\hline More than $1000 \mathrm{ppm}$ & 12 & 70.6 & 62 & 88.6 & $74(85.1)$ & \\
\hline \multicolumn{7}{|c|}{ 5. What is the daily frequency of brushing? } \\
\hline Twice or less & 1 & 5.9 & 52 & 74.3 & $33(60.9)$ & $p\left({ }^{*}\right)=0.00$ \\
\hline 3 times or more & 16 & 94.1 & 18 & 25.7 & $54(40.1)$ & \\
\hline \multicolumn{7}{|c|}{ 6. Does the child ingest toothpaste in other occasions? } \\
\hline Yes & 6 & 35.6 & 20 & 28.6 & $26(29.9)$ & $p(1)=0.587$ \\
\hline No & 11 & 64.7 & 50 & 71.4 & $61(70.1)$ & \\
\hline \multicolumn{7}{|c|}{ 7. Child washes the mouth after brushing? } \\
\hline Yes & 17 & 100.0 & 68 & 97.1 & $85(97.7)$ & $p(2)=1.000$ \\
\hline No & - & - & 2 & 2.9 & $02(3.7)$ & \\
\hline \multicolumn{7}{|l|}{ 8. Child spits after brushing? } \\
\hline Yes & 17 & 100.0 & 68 & 97.1 & $85(97.7)$ & $p(2)=1.000$ \\
\hline No & - & - & 2 & 2.9 & $02(3.7)$ & \\
\hline \multicolumn{7}{|l|}{ 9. Who brushes the child's teeth? } \\
\hline Child & 2 & 11.8 & 25 & 35.7 & $27(31.0)$ & $p\left({ }^{*}\right)=0.030$ \\
\hline Guardians & 15 & 88.2 & 45 & 64.3 & $60(69.0)$ & \\
\hline Total Group & 17 & 19.5 & 70 & 80.5 & $87(100.0)$ & \\
\hline
\end{tabular}

(*): Significant difference at 5.0\%. (1): Using the chi-square test. (2): Using Fisher's exact test. 


\section{Resumo}

0 objetivo do presente trabalho foi estimar a ingestão de flúor de dentifrícios utilizados por crianças de 2 a 6 anos de idade $(n=87)$ atendidas em um hospital de médio porte (Campina Grande, PB) na região nordeste do Brasil. Os dados envolveram características sócio-demográficas e escovação dentária das crianças através de uma entrevista com formulário específico, aplicado aos pais/responsáveis, e a quantidade de flúor utilizada na escovação da criança, por meio de balança de precisão, para avaliação do risco de fluorose dentária, considerando o ponto de corte $0,07 \mathrm{mgF} / \mathrm{kg}$ peso corporal/dia. 0 conteúdo de flúor nos cremes dentais foi analisado utilizando eletrodo específico. Os dados foram trabalhados sob a forma de estatística descritiva e inferencial usando o testes do Qui-quadrado de Pearson e Exato de Fisher $(\alpha=0,05)$. Levando-se em consideração o uso do dentifrício, o risco de fluorose das crianças pesquisadas foi 19,5\%. Houve associação significativa entre o risco de fluorose, a frequência de escovação, o tipo de dentifrício e quem realiza a higiene bucal da criança $(p<0,05)$. Concluiu-se que elevada parcela das crianças usavam o dentifrício de forma inadequada e apresentaram risco de fluorose.

\section{References}

1. Cury JA, Tabchoury CPM. Determination of appropriate exposure to fluoride in non-EME countries in the future. J Appl Oral Sci 2003;11:8395.

2. Burt BA. The changing patterns of systemic fluoride intake. J Dent Res 1992;71:1228-1237.

3. Leverett D. Prevalence of dental fluorosis in fluoridated and nonfluoridated communities - a preliminary investigation. J Public Health Dent 1986;46:184-187.

4. Ricomini Filho AP, Tenuta LMA, Fernandes, FSF, Calvo SCK, Cury JA. Fluoride concentration in the top-selling Brazilian toothpastes purchased at different regions. Braz Dent J 2012; 23:45-48.

5. Cury JA, Oliveira MJL, Martins CC, Tenuta LMA, Paiva SM. Available fluoride in toothpastes used by Brazilian children. Braz Dent J 2010;21:396-400.

6. Fomon SJ, Ekstrand J, Ziegler EE. Fluoride intake and prevalence of dental fluorosis: trends in fluoride intake with special attention to infants. J Public Health Dent 2000;60:131-139.

7. Fejerskov 0 , Manji $F$, Baelum $V$. The nature and mechanisms of dental fluorosis in man. J Dent Res 1990;8:15-31.

8. Mascarenhas AK, Burt BA. Fluorosis risk from early exposure to fluoride toothpaste. Community Dent Oral Epidemiol 1998;26:241-248.

9. Pereira AC, Cunha FL, Meneghim MC, Werner CW. Dental caries and fluorosis prevalence study in a nonfluoridated Brazilian community: trend analysis and toothpaste association. ASDC J Dent Child 2000;67:132-135.

10. Beltrán-Valladares PR, Cocom-Tun H, Casanova-Rosado JF, VallejosSánchez AA, Medina-Solis CE, Maupomé G. Prevalence of dental fluorosis and additional sources of exposure to fluoride as risk factors to dental fluorosis in schoolchildren of Campeche, Mexico. Rev Invest Clin 2005;57:532-539.
11. Jiménez-Farfán MD, Hernández-Guerrero JC, Juárez-López LA, JacintoAlemán LF, de la Fuente-Hernández J. Fluoride consumption and its impact on oral health. Res Public Health 2011;8:148-160.

12. Mascarenhas AK. Risk factors for dental fluorosis: A review of the recent literature. Pediatr Dent 2000;22:269-277.

13. Naccache H, Simard PL, Trahan L, Demers M, Lapointe C, Brodeur JM. Variability in the ingestion of toothpaste by preschool children. Caries Res 1990;24:359-363.

14. Conway DI, MacPherson LM, Stephen KW, Gilmour WH, Petersson LG. Prevalence of dental fluorosis in children from non-water-fluoridated Halmstad, Sweden: fluoride toothpaste use in infancy. Acta Odontol Scand 2005;63:56-63.

15. Tinanoff, N. A targeted program of providing 400-ppm F or 1450-ppm $\mathrm{F}$ toothpaste for low socioeconomic families was not associated with increased risk of esthetically objectionable fluorosis. J Evid Based Dent Pract 2007;7:21-22.

16. Franzman MR, Levy SM, Warren JJ, Broffitt B. Fluoride dentifrice ingestion and fluorosis of the permanent incisors. J Am Dent Assoc 2006;137:645-652.

17. Hong L, Levy SM, Broffitt B, Warren JJ, Kanellis MJ, Wefel JS, et al.. Timing of fluoride intake in relation to development of fluorosis on maxillary central incisors. Community Dent Oral Epidemiol 2006;34:299-309.

18. de Almeida BS, da Silva Cardoso VE, Buzalaf MAR. Fluoride ingestion from toothpaste and diet in 1- to 3-year-old Brazilian children. Community Dent Oral Epidemiol 2007;35:53-63.

19. Omena LMF, Silva MFA, Pinheiro CC, Cavalcante JC, Sampaio FC. Fluoride intake from drinking water and dentifrice by children living in a tropical area of Brazil. J Appl Oral Sci 2006;14:382-387.

20. Michel-Crosato E, Biazevic MGH; Crosato E. Relationship between dental fluorosis and quality of life: a population-based study. Braz Oral Res 2005;19:150-155.

21. Saravanan S, Kalyani C, Vijayarani MP, Jayakodi P, Felix AJW, Nagarajan $\mathrm{S}$, et al.. Prevalence of dental fluorosis among primary school children in rural areas of Chidambaram Taluk, Cuddalore District, Tamil Nadu, India. Indian J Community Med 2008;33:146-150.

22. van Loveren C, Ketley CE, Cochran JA, Duckworth RM, Mullane DM. Fluoride ingestion from toothpaste: fluoride recovered from the toothbrush, the expectorate and the after-brush rinses. Community Dent Oral Epidemiol. 2004;32:54-61.

23. Sampaio FC, Ramm von der Fehr F, Arneberg P, Petrucci Gigante $D$, Hatløy A. Dental fluorosis and nutritional status of 6- to 11-year-old children living in rural areas of Paraiba, Brazil. Caries Res 1999;33:6673.

24. EAPD. Guidelines on the use of fluoride in children: an EAPD policy document. European Archives of Paediatric Dentistry, 2009;10.

25. AAPD. Guideline on fluoride therapy. Pediatr Dent 2008;32.

Received October 31, 2012 Accepted April 2, 2013 